\title{
LAPSES, INFIDELITIES, AND CREATIVE ADAPTATIONS: LESSONS FROM EVALUATION OF A PARTICIPATORY MARKET DEVELOPMENT APPROACH IN THE ANDES'
}

\author{
Douglas Horton, Emma Rotondo, Rodrigo Paz Ybarnegaray, \\ Guy Hareau, André Devaux, and Graham Thiele
}

\section{Introduction}

Participatory approaches are often recommended to improve the efficiency and sustainability of international development programs or to contribute to local capacity development and empowerment (World Bank 1996;

Chambers 2010). Participatory approaches have a long history in agricultural research and development (R\&D), beginning with cropping- and farmingsystems research in the 1970s and evolving to a broad array of participatory approaches for rural assessment, plant breeding, natural-resource management, and market-chain development (Collinson 2000; Scoones and Thompson 2009; Devaux et al. 2009). Despite the extensive interest in and experimentation with participatory approaches over nearly a half-century, few of these approaches have been systematically evaluated and there is little evidence of their effectiveness and benefits (Martin 2009, 276; Johnson, Lilja, and Ashby 2003, 288).

Evaluators of participatory approaches have grappled with numerous challenges, including the broad range of expected project impacts, the large number of stakeholders with often differing interests, and the limited direct influence of evaluation results on funding decisions (Lilja and Dixon 2008a, 2008b). In this chapter, we address three even more fundamental methodological challenges to the evaluation of participatory approaches: the commonly

1 Thomas Bernet, Jason Donovan, and two anonymous reviewers provided valuable comments on earlier versions of this chapter. Jacqueline Ashby and Carlos Arturo Quiros made many valuable contributions to discussions about evaluation of participatory approaches in the Andean Change network. The United Kingdom's Department for International Development provided funding for the Andean Change Alliance and for the study reported on here. We would like to thank our local partners, collaborating women and men farmers, and others who took part in the work of Cambio Andino, without whom this work would not have been possible. 
imprecise definition of the approaches themselves; frequent adaptation of the approaches by local implementers; and the long, complex, and little-understood pathways through which participatory approaches contribute to such development goals as food security, rural livelihoods, and environmental sustainability.

From 2007 to 2010, the Andean Change Alliance ${ }^{2}$ evaluated four participatory approaches to agricultural R\&D (Thiele et al. 2011). Teams in Bolivia, Colombia, Ecuador, and Peru implemented the approaches with support from specialists based in two international agricultural research centers. ${ }^{3}$ A separate team (the authors of this chapter) evaluated the implementation and results of the approaches. A third team was tasked with using the evidence generated through evaluations for advocacy to promote more inclusive agricultural-innovation systems. ${ }^{4}$ One of the approaches evaluated was the Participatory Market Chain Approach (PMCA), developed by the International Potato Center and its Papa Andina partnership program (www.papandina.org). The PMCA engages smallholder farmers, market agents, and agricultural-service providers in a facilitated process that builds trust among these diverse groups and promotes collective action, which in turn leads to innovations that benefit smallholders as well as other chain actors.

In this chapter, we seek to advance thinking and practice in the planning, management, and evaluation of programs that involve participatory approaches, by reflecting on three aspects of the Alliance's evaluation work with the PMCA: (1) assessment of the fidelity of implementation; (2) identification of key factors that influence implementation and results; and (3) assessment

2 The Andean Change Alliance (Alianza Cambio Andino) was established to contribute to sustainable livelihoolds in poor communities by improving their participation in innovation processes (www.cambioandino.org). Funding and resources for the Alliance were provided by the United Kingdom Government's Department for International Development (DFID) and by participating organizations.

3 The two international centers were the International Potato Center (CIP) and the International Center for Tropical Agriculture (CIAT) (www.cgiar.org/about-us/research-centers/). Regional and national partners included: Programa para el Fortalecimiento de los Sistemas Gubernamentales de Seguimiento y Evaluación de Proyectos y Programas de Desarrollo Rural en América Latina y el Caribe (PREVAL); Asociación Colombiana de Organizaciones no Gubernamentales para la Comunicación Vía Correo Electrónico (COLNODO); Corporación para el Desarrollo Participativo y Sostenible de los Pequeños Agricultores (PBA Foundation, Colombia); Fundación para la Promoción e Investigación de Productos Andinos (PROINPA, Bolivia); and Instituto de Estudios Sociales y Económicos, Universidad Mayor de San Simon (IESE, Bolivia). The Alliance's work with the PMCA was implemented with Papa Andina (http://cipotato.org/att_ui/iniciativa-papa-andina/).

4 The importance of participatory approaches in agricultural innovation systems is noted in World Bank (2012). 
of the change model underlying the approach. We formulate lessons for improving future programs that employ the PMCA or other similar participatory approaches.

In the next section, we identify two contrasting perspectives found in the evaluation and innovation literatures on the importance of high fidelity of implementation versus the need for adaptation of interventions to fit local circumstances. Then, we describe the concepts and methods used in our study. After that, we describe the main features of the PMCA and then report on four applications of the approach in Bolivia, Colombia, and Peru. We then discuss the case-study results in relation to issues of fidelity of implementation, factors that influence implementation and results, and the PMCA change model, and discuss lessons for improving the planning, management, and evaluation of future programs involving participatory approaches such as the PMCA. The final section presents general conclusions.

\section{Perspectives on Fidelity and Adaptation}

One of the fundamental questions that drives evaluation is "Does an intervention work?' ... in the end we want to know whether a program did work, is working, or can work" (Century, Rudnick, and Freeman 2010, 199). Answering this deceptively simple question leads us to more fundamental questions such as: What is the intervention? How should the intervention be implemented? And how is the intervention expected to contribute to the intended results? The first two questions relate to what Chen (2005) calls the intervention's "action model" - a systematic plan for organizing resources, staff, and relationships in order to deliver the intervention faithfully. The third question relates to what Chen calls the "change model"-a broader conceptual framework that links the intervention's activities and outputs to the expected outcomes and impacts, and explains how and why the intervention is expected to lead to the desired changes.

The term fidelity of implementation refers to the extent to which a program's implementation is consistent with its action model. Researchers and evaluators have proposed frameworks for assessing fidelity of implementation based on such dimensions as adherence to protocol, exposure to services, quality of delivery, and participant responsiveness. Other frameworks for measuring fidelity are based on critical components of the intervention. Structural components relate to how the intervention is structured, the people and resources it mobilizes, and the tasks carried out. Process components relate 
to the principles and values underlying the intervention, the ways in which it is implemented, the skills, roles, and behaviors of the individuals involved in implementation, and the interactions among individuals and organizations (Zoch 2012). Based on the notion of critical components, Century, Rudnick, and Freeman $(2010,202)$ define fidelity of implementation as "the extent to which the critical components of an intended program are present when the program is enacted," and propose a framework for assessing the fidelity of implementation built around structural and process components.

Implementation evaluations generally focus on relatively easy-to-measure structural components. However, complex process components may have a greater influence on program outcomes (Bisset, Daniel, and Potvin 2009). We assess the fidelity of PMCA implementation using a framework with both structural and process components. We identify three main reasons why implementers deviated from the initial design of the PMCA, and discuss the implications for planning and managing programs that employ participatory approaches.

Publications on fidelity of implementation often stress the value of high fidelity and give the impression that infidelity is bad. This is because most of the fidelity literature is concerned with the measurement of intervention treatment effects. As Bierman (2006, 88-90) points out, interventions may fail due to problems with the action model, the change model, or the fidelity of implementation. If an intervention is not implemented according to plan, estimated treatment effects may be biased or misleading. Therefore, evaluators seeking to measure the validity of action or change models stress the importance of high implementation fidelity.

In contrast, studies concerned with innovation and the dissemination of new practices emphasize the positive aspects of adapting program procedures to fit local circumstances. Bierman (2006) highlights the need to balance tension between "research-based fidelity versus input and program adaptations offered by community members and local service providers." Ashley (2009, 37) notes that "diffusion theory anticipates modifications to interventions and purports that adaptability of the intervention to fit the context is critical to its adoption and maintenance over time." Patton (2011) argues that interventions that address complex social issues need to evolve and continuously adapt themselves to changing circumstances. Consequently, local teams should not be expected to implement intervention protocols mechanically, but should be encouraged to adapt interventions to achieve the best local results.

However, if local teams are encouraged to change any and all aspects of an intervention, they may forgo the potential value of applying key components 
of an intervention that are essential for its performance and impacts. Mowbray et al. $(2003,327)$ usefully highlight the importance of determining which components of an intervention are essential and which are optional:
Adaptation may be necessary due to special needs of the target popu- lation, differences in budget, community resources, or organizational factors... On the other hand, it is generally agreed that programs with higher fidelity to efficacious models produce superior outcomes...
Determining which components of the program are essential, irrespec- tive of context, and therefore require absolute fidelity to the original model, and which components may be modified, eliminated, or added, is an empirical matter.

In the work of the Andean Change Alliance, there was a continuous tension between the evaluators' desire to evaluate the validity of the PMCA action and change models and the desire of local teams to adapt the PMCA to fit their local circumstances. Reflection on this tension has helped us to distinguish between essential and optional components of the PMCA and balance concerns for fidelity and creative adaptation.

\section{Study Design and Methods}

When the Alliance began its work, no action and change models were available for the participatory approaches that were to be evaluated. Guides for users and trainers (Bernet, Thiele, and Zschocke 2006; Antezana et al. 2008) laid out the main elements of the PMCA and a set of tools that could be used to implement the approach. But there was no protocol to guide implementation, nor were there indications of how the protocol should be used by individuals and organizations working with target populations within specific organizational and agroecological contexts. Similarly, PMCA specialists had general ideas about how the approach could contribute to changes at the level of individuals and groups, and how these changes could benefit smallholder farmers and other stakeholders, but these ideas had not been documented or critically assessed.

\section{Elaboration of PMCA Protocol and Impact Pathway}

One of the first activities of the Alliance's evaluation group was to organize a workshop in which PMCA specialists and members of the Alliance formulated an implementation protocol and a hypothetical impact pathway for the PMCA (Alvarez et al. 2008). The initial versions of these instruments were 
subsequently revised periodically on the basis of experience and knowledge gained during PMCA implementation (Table 13.1 and Figure 13.1).

Based on the PMCA User Guide and specialist knowledge, the implementation protocol identifies key structural elements of the PMCA and the associated implementation processes. We later developed an instrument for scoring the fidelity of implementation of the PMCA, based on the implementation protocol (Table 13.3). Workshop participants also articulated a change model in the form of an "impact pathway," drawing on a methodology known as Participatory Impact Pathway Analysis (Douthwaite et al.

TABLE 13.1 Participatory market chain approach (PMCA) implementation protocol

\begin{tabular}{|c|c|}
\hline Structural components & Process components \\
\hline \multicolumn{2}{|l|}{ Phase 1. Diagnostic phase (3 months) } \\
\hline Actor mapping & \multirow{2}{*}{$\begin{array}{l}\text { - The facilitator leads activities that generate the interest of } \\
\text { diverse market-chain actors in participating in the PMCA } \\
\text { exercise } \\
\text { - The principal market-chain actors are identified and known }\end{array}$} \\
\hline $\begin{array}{l}\text { Qualitative diagnosis of the market } \\
\text { chain, to identify problems, potential } \\
\text { business opportunities }\end{array}$ & \\
\hline Public event at end of Phase 1 & $\begin{array}{l}\text { - The principal market-chain actors participate in the event } \\
\text { - Potential business opportunities are identified } \\
\text { - Thematic groups are established } \\
\text { - Results of the event are documented in a meeting report }\end{array}$ \\
\hline \multicolumn{2}{|c|}{ Phase 2. Analysis of business opportunities (3-4 months) } \\
\hline $\begin{array}{l}\text { Meetings approx. every } 15 \text { days with } \\
\text { diverse market chain actors, for: } \\
\text { - Analysis of market opportunities } \\
\text { - Market studies } \\
\text { - Analysis of costs } \\
\text { - Business planning }\end{array}$ & $\begin{array}{l}\text { - Interaction among diverse market-chain actors to generate } \\
\text { confidence among them } \\
\text { - Development of at least one business plan } \\
\text { - Facilitators should ensure the ample participation of market- } \\
\text { chain actors, especially small farmers, in decisionmaking } \\
\text { during Phases } 2 \text { and } 3\end{array}$ \\
\hline Public event at end of Phase 2 & $\begin{array}{l}\text { Progress is shared and new participants / allies are included, } \\
\text { who can enrich joint activities }\end{array}$ \\
\hline \multicolumn{2}{|c|}{ Phase 3. Implementation of business opportunities (3-6 months) } \\
\hline $\begin{array}{l}\text { Meeting approx. every } 15 \text { days with } \\
\text { diverse actors, to implement business } \\
\text { opportunities }\end{array}$ & \multirow{4}{*}{$\begin{array}{l}\text { - Joint activities/collaboration to implement new business } \\
\text { opportunities with market-chain actors playing a leading role } \\
\text { - Communication and negotiation among market-chain actors } \\
\text { - Small farmers increase their knowledge of the market chain }\end{array}$} \\
\hline Specific market studies & \\
\hline Specific technical studies & \\
\hline Product development & \\
\hline Public event at end of Phase 3 & $\begin{array}{l}\text { - Innovations are launched } \\
\text { - Members of the press, opinion leaders, and relevant political } \\
\text { authorities participate, to ensure ample communication and } \\
\text { diffusion of results and support for the PMCA exercise }\end{array}$ \\
\hline
\end{tabular}

Source: Authors.

Note: This formulation of the PMCA protocol is inspired by the framework proposed by Century, Rudnick, and Freeman (2010). 


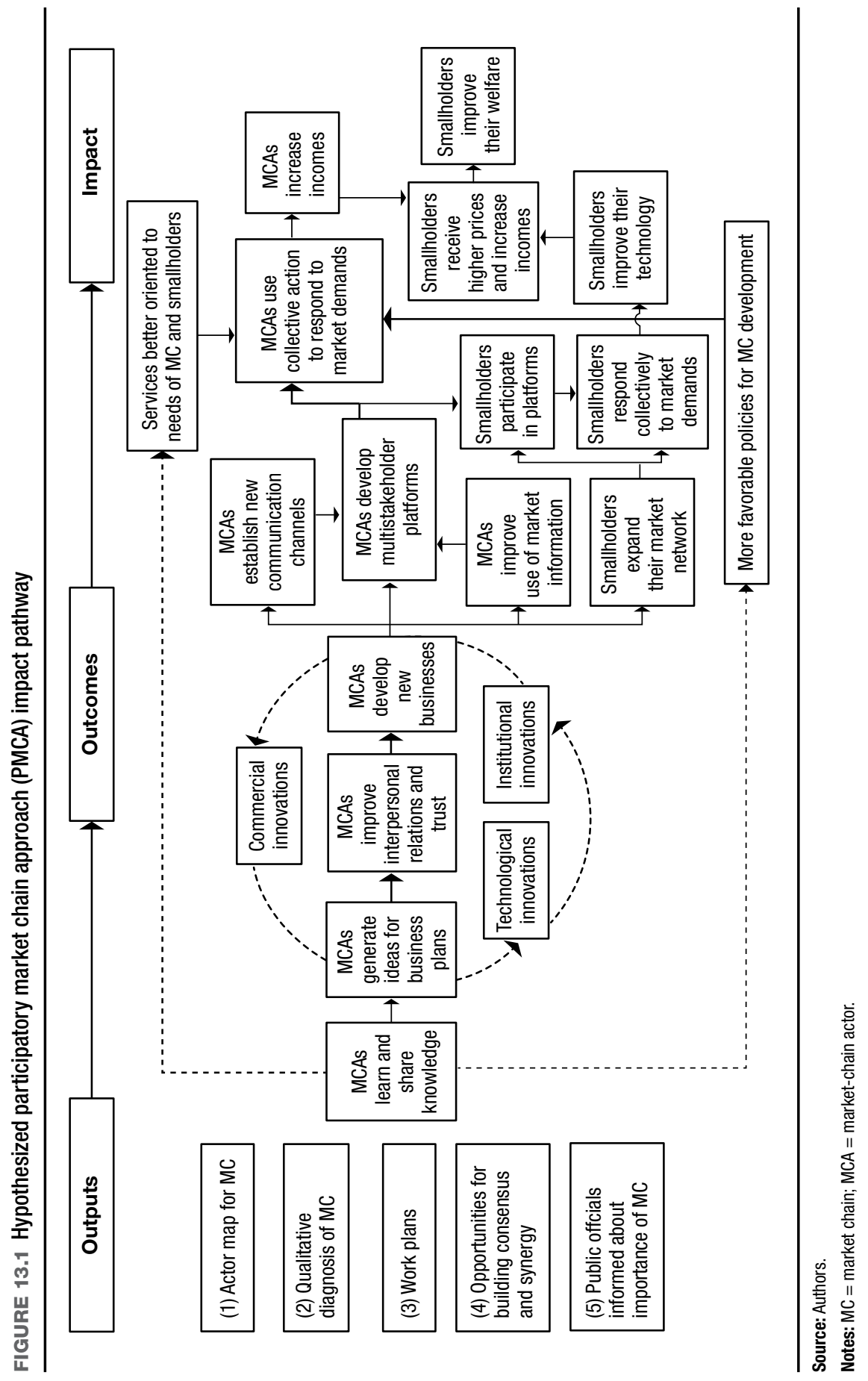


2007; Alvarez et al. 2010). The hypothetical impact pathway illustrates the main channels and processes through which the outputs of the PMCA are expected to contribute to the welfare of smallholder farmers. On the basis of the impact pathway, we developed an instrument for scoring progress toward achievement of the goals of the PMCA (Table 13.4). The coauthors of this chapter scored the fidelity of implementation and progress along the impact pathway for each case.

\section{Analysis of Factors that Influenced Implementation and Results}

Our analysis of the factors that influence PMCA implementation and results is based on the Institutional Analysis and Development (IAD) framework developed by Ostrom (2005) and modified by Devaux et al. (2009) and Horton et al. (2011) (Figure 13.2). The innovation process is viewed as a complex system that operates within a larger "macro context." The heart of the system is the "innovation arena" where interactions among diverse market-chain actors and service providers stimulate social learning, social-capital formation, and joint innovation processes. These processes strengthen the system's capacity for innovation and generate commercial, technical, and institutional innovations. In this framework, innovation processes and results are influenced by four sets of independent variables:

1. Macro context: Includes the government policies, socioeconomic conditions, and agroecological characteristics of the region that influence market-chain development.

2. Market chain: Biophysical and technological characteristics of the market chain in which the PMCA is being applied.

3. Principal actors: Attributes of relevant market-chain actors and service providers.

4. Rules in use: Formal and (mainly) informal norms and customs that govern the behavior of participants.

We return to this framework in our analysis of factors that influenced the implementation and results of the PMCA in the Discussion.

\section{Baseline Studies}

Before initiating work with the PMCA, baseline studies were to be carried out at each local site. Information on livelihoods and household assets was gathered for a sample of households in communities where the PMCA was to be applied 
FIGURE 13.2 Framework for analyzing market-chain innovation processes

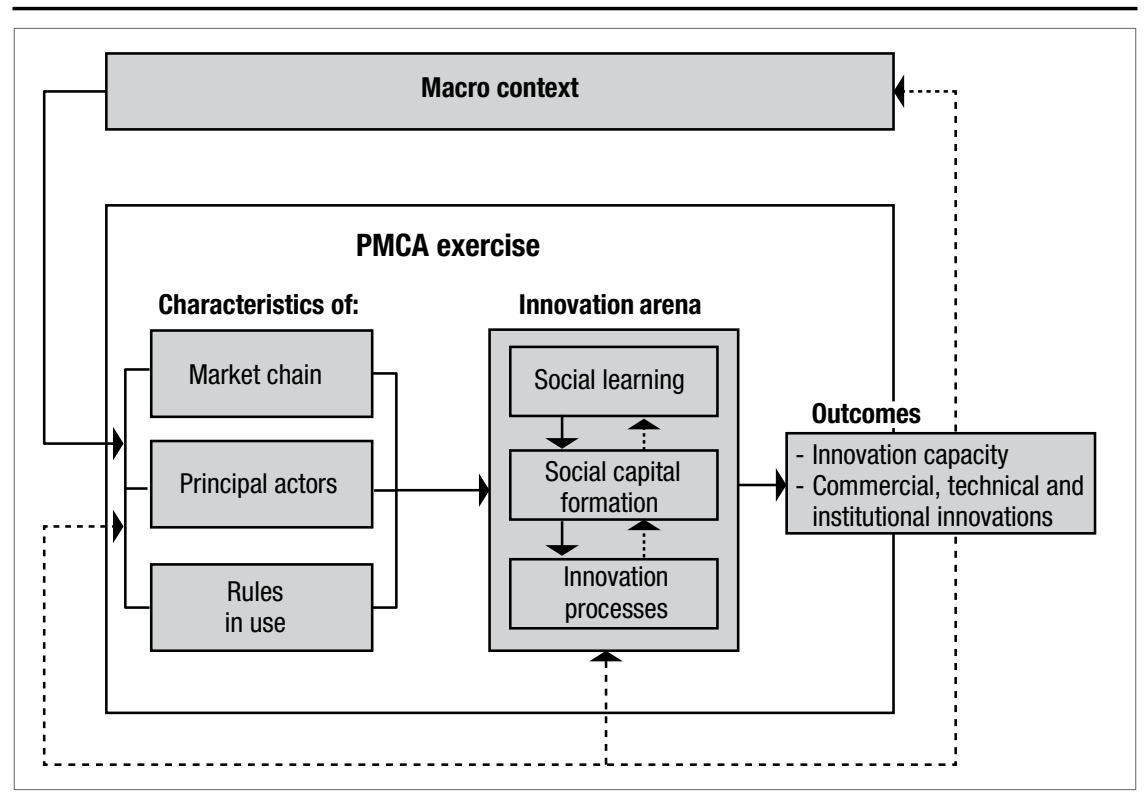

Source: Horton et al. (2011).

and in nearby communities that were considered to be comparable, and which were intended to serve as control treatments in a quasi-experimental research design. A substantial amount of time and resources went into the planning and administration of the household surveys needed to collect the baseline data. The data collected proved useful for characterizing the communities where the participatory approaches were being tested and for ascertaining that the communities were comparable to others in the same geographic area. However, they were less useful for evaluation purposes, for four reasons: First, in some cases, the "control community" turned out to be substantially different from the community where the PMCA was to be tested. Second, planning and administering the household surveys took longer than anticipated, and in some cases the implementation teams began work with the PMCA before the surveys were completed. Third, in some cases, after the surveys were completed, implementation teams decided to work with different communities or groups. Fourth, when we planned the baseline studies there was a possibility of a second phase for the program, which would have given more time for measurable outcomes to emerge. Due to changes in funding policies for international agricultural research, this second phase never materialized, leaving us with less than two 
years between program completion and final evaluation. In light of the long and complex pathway connecting the PMCA with rural livelihoods and assets, when the Alliance ended its work it was too early to expect to be able to measure changes in household livelihoods or assets.

\section{Process and Outcome Monitoring and Evaluation}

The Alliance's evaluation team periodically monitored PMCA implementation processes and products, evaluated outcomes at the end of each application, and produced a series of monitoring and evaluation reports. In 2010, an external consultant led a synthesis exercise that documented overall results and drew lessons from a set of case studies (Horton et al. 2011).

\section{Case Studies}

Eight applications of the PMCA were initiated under the leadership of professionals in agricultural R\&D organizations in Bolivia, Colombia, Ecuador, and Peru. None of the professionals who were responsible for leading the PMCA exercises had implemented the approach previously. The Alliance organized PMCA training events and provided backstopping and coaching during the implementation of each case. Of the eight PMCA exercises initiated, five were completed (Table 13.2). There were various reasons for early termination of the other three exercises. Work with dairy products in northern Peru was one of the first cases implemented, and its supervision and facilitation were less than ideal. Rather than identifying a market opportunity, the group focused on a production problem. Since production problems were not the appropriate focus of a PMCA exercise, the Alliance shifted its support in Peru from the dairy case to the coffee case in San Martin, which was being implemented by the same NGO. In Santa Cruz, Bolivia, the agricultural research organization attempted to shorten the PMCA implementation period by skipping most of Phase 2, which is essential for building trust among market-chain actors. They jumped directly to joint action between farmers and processors, and were dismayed when the farmers did not accept a contract to supply peaches to a catering company. Even though the price offered was attractive, farmers would have needed more personal interaction with company representatives before agreeing to such a contract.

Our analysis focuses on the four completed cases that we believe offer the richest potential for learning within the resources available for the study:

- Case 1. Developing and marketing new dairy products in Oruro, Bolivia

- Case 2. Conserving and marketing native potatoes in northern Potosi, Bolivia 
TABLE 13.2 Participatory market chain approach (PMCA) applications associated with the Andean Change Alliance

\begin{tabular}{lcc}
\hline Case & Completed & Included in this study \\
\hline Bolivia & & \\
\hline Developing and marketing new dairy products in Oruro & Yes & Yes \\
Conserving and marketing native potatoes in northern & Yes & Yes \\
Potosi & No & No \\
Fruit in Santa Cruz & No & No \\
Vegetables in Santa Cruz & & \\
\hline Colombia & Yes & \\
\hline Developing new markets for yams (north coast of & & No \\
Colombia) & & \\
\hline Ecuador & Yes & Yes \\
\hline Promotion of native potatoes, Riobamba & & No \\
\hline Peru & Yes & No \\
\hline Marketing high-quality coffee in San Martin & & \\
Dairy products, Cajamarca & & \\
\hline
\end{tabular}

Source: Authors.

- Case 3. Developing new markets for yams in northern Colombia

- Case 4. Marketing high-quality coffee in San Martin, Peru

The fifth completed case (Promotion of native potatoes in Riobamba, Ecuador) was excluded from the in-depth study because there had been significant departures from the PMCA protocol, and including fieldwork in Ecuador would have entailed substantial additional expense.

Following Yin (2009), a case-study protocol guided the collection and analysis of information in the four cases. Information sources included the Alliance's extensive monitoring and evaluation reports, other published and unpublished documents, visits to each field site, and key-informant interviews with stakeholders.

\section{Validation of Findings}

Various approaches were used to validate case-study findings, including: triangulation of information sources; presentation and feedback sessions with stakeholders at the end of each country visit; presentation and discussion of general findings in a regional workshop after completion of the four case studies; and circulation of drafts of a research report to stakeholders for comment and correction. This chapter's authors independently scored implementation 
fidelity and progress along the hypothetical impact pathway and discussed reasons for differences in reaching a consensus on the scores.

\section{The Participatory Market Chain Approach}

The PMCA was originally developed to stimulate innovation processes that would benefit small Andean farmers. The approach engages those who make their living from a market chain-market-chain actors-as well as agricultural-service providers in facilitated group processes aimed at identifying and exploiting new market opportunities in ways that benefit small farmers. The PMCA is designed to build the capacity of market-chain actors and empower them to innovate on their own. Applications of the PMCA should be guided by trained PMCA facilitators based in local R\&D organizations who understand the PMCA implementation protocol as well as the principles underlying the approach.

The PMCA is implemented in three phases (see Figure 7.2). During Phase 1, facilitators should familiarize themselves with the target market chain and its actors, share this knowledge with stakeholders of the market chain, and motivate them to participate in the PMCA application. This phase is expected to take 2 to 4 months and may involve 20 to 40 interviews with diverse market-chain actors. It ends with a public event that brings together individuals who have been involved, to discuss results of the market survey, exchange ideas, and set up thematic groups. Important actors who have not been involved so far are also invited to this event, to stimulate their interest and motivate them to participate in future activities.

During Phase 2, potential business opportunities should be identified and assessed. The PMCA facilitator organizes and facilitates regular thematic meetings where market opportunities are identified and discussed. These also build up mutual trust and knowledge sharing among participants. The participation of market-chain actors other than farmers is essential to maintain a focus on market demands and opportunities. Six to ten meetings are recommended and rapid market appraisal and focus-group studies are usually carried out to assess market potential and develop product concepts. At a final event, the business opportunities are discussed with a wider audience.

During Phase 3, market-chain actors are expected to work together to develop new products and production or marketing processes, with support from research or other service organizations, such as universities or food-technology laboratories. This phase focuses on the activities needed 
to launch specific innovations. The time required may vary from 3 to 6 months, depending upon the complexity of the innovation, the capacity of the group, and biophysical, socioeconomic, and institutional conditions. Phase 3 closes with a large public event where new market products and related innovations are launched. Although the PMCA formally ends with the public launch of innovations, the innovation processes may continue long afterward.

\section{Four Applications of the PMCA}

This section presents summaries of four case-study reports that are available in Horton et al. (2011). Each case summary includes information on:

- Context of the PMCA exercise: the macro context, biophysical and technical characteristics of the market chain, attributes of market-chain actors and service providers, and the prevailing norms and customs

- Implementation of the PMCA: participants and the timeline of main activities

- Results of the PMCA: commercial, technological, and institutional innovations, changes in innovation capacity, contributions to welfare.

\section{National Macroeconomic Environment}

A country's economic policies can strongly influence the use and results of market-chain development approaches, such as the PMCA. When the PMCA was being applied, the governments of Colombia and Peru pursued economic policies that promoted market-led development through promotion of competitive markets, international trade, and private-sector investment. In contrast, the Bolivian government emphasized state-led investment and regional and indigenous development, food sovereignty, and conservation of natural and cultural resources. The economic policies of Colombia and Peru could be seen as more favorable than those of Bolivia for the use of market-development interventions such as the PMCA.

\section{Case 1. Developing a Local Market for Quality Coffee in Peru's High Jungle}

CONTEXT

Peru's San Martin province produces high-quality coffee for specialty export markets, but local people consume little coffee, and mostly instant coffee. The 
international NGO Practical Action worked in San Martin for more than a decade to promote sustainable and equitable development of the coffee industry. Until recently, together with the regional government and local R\&D organizations, they focused on improving production and postharvest practices. A "coffee round table" was set up to bring together stakeholders, market-chain actors, and agricultural-service providers. A local women's group processed and marketed regional foods, but did not work with coffee. With the PMCA, Practical Action and the women's group took the lead in developing a local market for locally produced coffee.

\section{IMPLEMENTATION}

The PMCA was applied over a period of 16 months beginning in June 2007. An employee of Practical Action played a key role in facilitating the exercise and supporting local initiatives. The women's group led the development of the local coffee sector with other stakeholders. After completion of the PMCA, Practical Action continued to support efforts to develop the local coffee market, through establishment of an association of artisanal coffee processors.

\section{OUTCOMES}

Members of the women's group gained knowledge and skills in coffee processing and marketing, and developed a new coffee brand that has now been on the local market for more than 3 years. The new brand incorporates more careful selection of coffee beans and improvements in roasting, grinding, and packaging. The PMCA exercise and follow-up since 2008 have also motivated greater networking and relationship building among different stakeholders. In 2010, a public event to promote the region's coffee attracted local authorities, private-sector organizations, media, and about 500 members of the public. Success with coffee marketing has helped consolidate the women's group and raise its visibility in public and policy circles, as well as in emerging fairs and markets for organic produce. They now play a much more prominent role in the local food system.

\section{Case 2. Developing and Marketing New Dairy Products in Highland Bolivia}

\section{CONTEXT}

Agriculture and livestock herding in Oruro, Bolivia, are challenged by the cold, dry environment, and low rural population density, raising the local production costs. Over the past 30 years, micro-irrigation has stimulated smallscale cropping and dairy herding near the city. The Danish International 
Development Agency and other development organizations have encouraged and supported farmer self-help groups that operate community-based dairy processing plants. Dairy specialists who worked in aid programs have established a foundation, Fundación de Servicios para el Desarrollo Rural Agropecuario, Bolivia (SEDERA), which offers technical services and support to small herders and dairy processors. In recent years, the market for dairy products has become increasingly competitive as multinational firms have developed sophisticated production and distribution systems that reach Oruro, making a wide range of products available at competitive prices.

\section{IMPLEMENTATION}

The PMCA was implemented during 20 months beginning in October 2007. SEDERA led and facilitated the PMCA application with the goal of diversifying the production of community-based dairy plants. One objective was to produce mozzarella cheese to supply local pizzerias. Bolivia's Foundation for Promotion and Research of Andean Products (PROINPA) and Papa Andina organized training events at the beginning of each phase. Technical training in mozzarella preparation was provided by cheese makers from Argentina, who adapted methods used in their country to the local environment and input supplies. Market-chain actors and other stakeholders seldom came together for face-to-face meetings, partly because small herders live scattered over the rural landscape, and partly because SEDERA was more comfortable working with farmers than with market agents. Midway through the PMCA exercise, the farmer organization withdrew because they obtained a more attractive outlet for their milk, and a new farmer organization joined the process. This slowed down implementation of the exercise.

\section{OUTCOMES}

SEDERA and the local farmer group were successful in producing mozzarella cheese that met local quality requirements. The new cheese, marketed under the "Vaquita Andina" brand, has been available for two years in a store operated by SEDERA and in some high-end food markets, including a supermarket in Oruro. Work with the PMCA has motivated local dairy producers to diversify the types of cheese they produce and to upgrade quality and sanitary standards. Due mainly to its relatively high price, the new mozzarella cheese is not used by local pizzerias-the original goal. The main consumers are high-income households willing to pay a premium for a naturally produced local cheese. Economic benefits for small producers have been limited. SEDERA has gained expertise in market-chain analysis and in facilitating 
innovation processes, and is now using a more integral, market-oriented approach to its development work.

\section{Case 3. Conserving and Marketing Native Potatoes in Highland Bolivia}

\section{CONTEXT}

Known as a mining region and home to one of the poorest rural populations in Latin America, one of Bolivia's northern Potosi underexploited resources is the genetic diversity of its native potatoes. PROINPA and the Center for Agricultural Development (CAD) have worked for several years to conserve the biodiversity of the potato and other Andean crops and to reduce rural poverty.

\section{IMPLEMENTATION}

Facilitated by CAD, the PMCA was applied over 17 months (beginning in May 2007) to develop markets for the native potatoes produced by small farmers in the region. PROINPA, Papa Andina, and other service providers backstopped and also provided technical support for organic potato production and postharvest technology. CAD prioritized strengthening farmer associations and establishing a network of associations, to coordinate marketing and improve farmers' negotiating power. They assisted these groups in marketing their potatoes and developing proposals for a potato-processing plant. There was little interaction with local market intermediaries.

\section{OUTCOMES}

A new potato product branded "Miskipapa" was developed, which consists of selected and washed native potatoes sold in net bags. It has been marketed for three years in supermarkets in La Paz and Cochabamba, in the store of a mining union, in two tourist hotels, and in farmers' markets. Due to limitations in both the supply and demand of native potatoes, economic benefits to farmers appear to be small. However, increased awareness about their value has contributed to renewed efforts to conserve the biodiversity of native potatoes in the region. To market Miskipapa, farmers have improved the selection and sorting of their harvested potatoes. CAD continued to support the farmer organization with their marketing initiative. Despite the fact that they expressed interest, little support from local governmental bodies has materialized. Perhaps the most significant outcome has been the expertise gained by CAD, which prompted shifting its emphasis from production development to market-chain innovation. 


\section{Case 4. Developing New Markets for Yams on the North Coast of Colombia}

\section{CONTEXT}

Yams were introduced together with slaves from West Africa, and are now one of the main crops grown by poor farmers on the north coast of Colombia. Here, the distribution of landholdings is extremely skewed, contributing to rural poverty and social inequality. Combined with the presence of drug-related conflict, violence erupted at the end of the 1990s and continued for nearly a decade. Despite the insecurity, a few development organizations continued to work in the areas promoting rural development.

\section{IMPLEMENTATION}

The PBA Foundation is a nonprofit organization that works with international development agencies and local partners to promote participatory innovation processes among small farmers. In 2006, it launched an initiative to improve the marketing of the products produced by region's small farmers. In April 2008, the Foundation incorporated the PMCA and facilitated its implementation in seven market chains over a 13-month period. An expert from Papa Andina backstopped the work. Three potential areas for commercial innovation were identified:

- Production of yam flour for specialty uses in cosmetology and baking

- Exportation of fresh yams to the United States

- Domestic marketing of high-quality fresh yams.

A local university carried out applied technical and market research in these areas, business plans were developed, and new products were pilot tested with potential buyers. After completion of the exercise, the Foundation has worked to establish a network of local associations to promote development of the yam sector.

\section{OUTCOMES}

Some progress was made in improving the domestic marketing of yams, but no distinctive new yam product was developed and marketed. To sell higherquality yams at premium prices, small farmers have increased planting density, and improved the selection and cleaning of harvested tubers. A few shipments of fresh yams have been made to the United States, but development of this market faces steep competition from other Caribbean suppliers. Commercial 
testing of high-quality yam flour has been hampered by lack of resources for construction of a pilot plant. The PBA Foundation has incorporated elements of the PMCA into its portfolio of participatory methods. In light of the small size of local farmer organizations, the PBA Foundation has worked to establish a regional network of local associations to improve the performance of marketing functions. One unanticipated result of this case has been the organization of venders within the local market, to coordinate the flow of produce and reduce price variability.

\section{Discussion}

This section analyzes the fidelity of implementation of the PMCA, the factors that influenced implementation and results, and the validity of the PMCA change model.

\section{Fidelity of Implementation}

Most of the activities prescribed for Phase 1-the diagnostic phasewere implemented with reasonable or high levels of fidelity (Table 13.3). Diagnostic studies of the target market chains were carried out and the results were shared with stakeholders at public events. In three of the four cases, these public events were well attended by market-chain actors, service providers, and local policymakers, attracting 50 or more participants, reflecting stakeholder interest in developing the local dairy market chain. In Phase 2-the potential-business analysis phase-the fidelity of implementation was high in two of the cases, but lower in the other two cases. Case 2 (native potatoes in Bolivia) was particularly weak, with few group meetings and little diversity among the participants. Few market agents participated in these meetings, violating a core principle of the PMCA, which promotes innovation through the interaction of diverse market-chain actors, including market agents. In Phase 3-the implementation phasethe fidelity of implementation was high only in the coffee-processing case in Peru. Here, group meetings were frequently held and market-chain actorsin this case, a women's processing and marketing group-played a lead role in new product development. In the other three cases, the facilitators continued to lead the innovation processes, rather than turning over responsibilities to local market-chain actors.

There are many possible reasons for diverging from the intervention protocol, and the cases show that not all of them are bad. Implementers often felt the need to creatively adapt implementation procedures to fit local 
TABLE 13.3 Scoring of the fidelity of implementation of the participatory market chain approach (PMCA)

\begin{tabular}{llccc}
\hline Activity and quality parameter & \multicolumn{5}{c}{ Scores for each case } \\
\cline { 2 - 6 } & Case 1 & Case 2 & Case 3 & Case 4 \\
\hline Phase 1. Diagnostic phase (3 months) & & & & \\
\hline Market chain is mapped and main MCAs are interviewed & 3 & 2 & 2 & 2 \\
- At least 20-40 diverse MCAs are interviewed & 3 & 2 & 2 & 2 \\
- Bottlenecks and opportunities are identified & 2 & 2 & 2 & 2 \\
- MCAs are motivated to participate in PMCA & & & & \\
\hline Public event at end of Phase 1 & 3 & 1 & 2 & 3 \\
- Key MCAs and service providers attend & 3 & 3 & 3 & 3 \\
- Results of market study are presented and discussed & 3 & 2 & 2 & 3 \\
- Interest in further collaboration is generated & 3 & 3 & 3 & 3 \\
- Thematic groups are established & &
\end{tabular}

Phase 2. Analysis of business opportunities (3-4 months)

Meetings to analyze market opportunities and plan business

- Meetings approximately every 15 days

- Interaction among diverse MCAs to generate confidence

$\begin{array}{llll}3 & 1 & 3 & 3\end{array}$

- Development of at least one business plan

$\begin{array}{llll}2 & 1 & 2 & 2\end{array}$

Public event at end of Phase 2

- Key actors attend

$\begin{array}{llll}3 & 3 & 3 & 3\end{array}$

- Progress is shared

$\begin{array}{llll}3 & 2 & 2 & 3\end{array}$

- New participants are engaged to enrich joint activities

$\begin{array}{llll}3 & 2 & 2 & 3\end{array}$

Phase 3. Implementation of business opportunities (3-4 months)

Meeting for joint implementation of business opportunities

- Meetings approximately every 15 days

$\begin{array}{llll}3 & 2 & 1 & 3\end{array}$

- Diverse MCAs engaged in PMCA application

- Market-chain actors play a leading role

\begin{tabular}{llll}
3 & 1 & 1 & 0 \\
2 & 1 & 1 & 0 \\
2 & 0 & 0 & 1 \\
\hline
\end{tabular}

Technical and market studies carried out

- Studies carried out

- Studies inform group decisions

New products developed

- Prototype is tested with consumers and markets

$\begin{array}{llll}3 & 3 & 3 & 1\end{array}$

Public event at end of Phase 3

- Innovations are launched

$\begin{array}{llll}3 & 3 & 3 & 1 \\ 3 & 3 & 3 & 3\end{array}$

- Opinion leaders and political authorities participate

Source: Authors.

Notes: 0 =absent; 1 = present with low quality; 2 = moderate quality, $3=$ high quality; MCA = market-chain actor. 
circumstances, while respecting the basic principles underlying the action and change models. Many useful creative adaptations were made. For example, in Bolivia, a single set of training workshops was organized for two different cases; on the north coast of Colombia, a single set of training workshops was held for facilitators and chain leaders in seven different market chains. Such adaptations should be encouraged to improve the cost-effectiveness and results of the intervention.

Where implementers did not fully understand the intervention protocol or the underlying action and change models, or they lacked the capacity or resources needed to implement the intervention as designed, unintended lapses occurred. The two cases in Santa Cruz, Bolivia where facilitators attempted to skip over Phase 2 of the PMCA are examples of lapses. In many cases, lapses can be remedied through training or assisting local implementers to gain access to the resources needed to implement the intervention as designed.

The most problematic types of divergence from the intended protocol were true infidelities, which occurred when local implementers intentionally violated core principles of the intervention. Such infidelities are especially problematic in participatory interventions, which seek to empower local actors. If important goals of the intervention are empowerment and innovation, then local actors should be encouraged to take responsibility and creatively adapt the intervention to fit local conditions. In Case 2 (native potatoes), the focus on working with small farmers rather than diverse market-chain actors is an example of an infidelity that reflected local implementers' belief that the intervention should focus on strengthening farmer organizations rather than bringing farmers together with market-chain actors to work on joint innovations. This view may be valid in the local conditions of Bolivia's altiplanoone of the harshest and poorest regions in Latin America. However, the point remains that intentional deviations from the protocol that include elimination of essential components of the intervention-such as the engagement of diverse market-chain actors in the PMCA-are both difficult (or impossible) to correct during implementation, and make it impossible to test the validity of the intervention's action or change models.

\section{Factors that Influence Implementation and Outcomes}

The IAD framework suggests four main groups of factors that may influence the implementation and results of the PMCA. Our studies bear out the importance of these factors and also suggest the importance of an additional group of factors related to the strategy used to develop local capacity for use of the PMCA. 


\section{MACRO CONTEXT}

The pro-market policies of Colombia and Peru provided a more favorable environment for use of the PMCA than did the policies of the Bolivian government, which emphasize the role of the state and "communitarian socialism." The more favorable agroecological environments in which the Colombian and Peruvian exercises were carried out also appear to have favored the implementation processes and outcomes. In the Bolivian altiplano, where poverty is more severe than in practically any other part of Latin America, there appear to be severe limits to the potential contributions of agricultural market-chain development approaches to rural poverty reduction.

\section{ATTRIBUTES OF THE MARKET CHAIN}

Successful innovation is more likely in some market chains than in others. In the cases involving coffee, and to a somewhat lesser extent dairy, it has been possible to mobilize external knowledge to improve processing. In contrast, in the cases of native potatoes and yams, the global knowledge base is more restricted. Especially for yams, little scientific information is available in Spanish. Coffee and dairy products are also more amenable to processing, branding, and product differentiation than are potatoes and yams. Processing of native potatoes for chips has emerged as a viable enterprise catering to high-income urban consumers in Peru and to a lesser extent in Bolivia, but this type of industry is typically located in urban areas, and was not considered as a likely option for the potato case in Bolivia.

\section{ATTRIBUTES OF INDIVIDUALS}

Our cases indicate that three distinct types of champion may be crucial for successful implementation of the PMCA and for mainstreaming the approach in R\&D organizations. The first type of champion is the PMCA facilitator, who forms commodity groups and mediates innovation processes; the second type is a senior manager / decisionmaker who facilitates resource mobilization for the PMCA, as well as mainstreaming use of the approach; the third type of champion is a recognized leader within the market chain. In Case 1, the facilitator based in Practical Action played a key role in identifying and supporting local actors and facilitating change processes within the coffee market chain. A senior manager within Practical Action provided strong institutional support for the work. Within the coffee market chain, the leader of the women's processing group led in developing the new brand of coffee and networking with others to develop the local coffee sector; leadership and capacity to invest 
in the private sector are crucial for the ultimate success of efforts to stimulate market-chain innovation.

\section{RULES IN USE}

Rules in use refer to the social structures, mechanisms, customs, norms, and rules - both formal and informal - that guide human behavior on a day-today basis. In our cases, rules in use strongly influenced the marketing and innovation behaviors of individuals and groups. In fact, a central goal of the PMCA is to modify the customary patterns of behavior and interaction so as to stimulate innovation and improve the participation of smallholder farmers in dynamic markets.

The market chains we worked with were generally characterized by distrust and limited communication and interaction among the different chain actors (for example, producers, rural assemblers, processors, and retailers), which limits coordination and collaboration. Distrust, poor communication, and limited interaction were perhaps most notable in the native-potato market of highland Bolivia, where urban-based market agents consider themselves superior to indigenous farmers and discriminate against them in many ways. Notable racial and cultural differences were also present in the market chain for yams on the north coast of Colombia. In the local coffee market in Peru's high jungle, the relative absence of ethnic and racial cleavages and discrimination facilitated the interaction of diverse market-chain actors and the emergence of collective action.

The rules in use (or "standard operating procedures") of R\&D organizations are also important. The PMCA is facilitated by individuals based in $\mathrm{R} \& \mathrm{D}$ organizations that have particular mandates, program structures, cultures, norms, and external relationships. The mandate and culture of agricultural research organizations can pose challenges for successful application of the PMCA, because these organizations may be averse to working with private businessmen engaged in processing and marketing. The implementing organizations in Bolivia and Colombia traditionally work with farmers to improve their operations, and this helps explain why they failed to thoroughly engage processors and other market actors during the PMCA. In contrast, the implementing organization in Peru-Practical Action-has a strong tradition of working across sectors, and it readily incorporated the PMCA into its program to develop coffee markets in Peru. 


\section{CAPACITY-DEVELOPMENT STRATEGY}

The capacity-development strategy varied across the cases, explaining some of the differences in implementation fidelity and results. Some departures from the PMCA protocol occurred because facilitators lacked a thorough understanding of the principles underlying the PMCA and how they are reflected in the intervention protocol. In the Peruvian case there were no formal training events. Instead, a market-development specialist at the Andean Change Alliance traveled to San Martin to provide one-onone training, backstopping, and mentoring for the local facilitator and the group that was applying the PMCA. In the other three cases, formal training workshops were organized for local facilitators at the beginning of each phase of the PMCA, and the Alliance's market-development specialist was less involved in these cases. In Bolivia, trainers from the Alliance and PROINPA delivered these workshops and backstopped local facilitators. PROINPA's agricultural R\&D mandate appears to have biased the training and backstopping toward working with groups of small farmers rather than market agents. Experience with these and other applications of the PMCA (Horton et al. 2012; Mayanja et al. 2012) shows the value of immersion-type training and visits to sites where the PMCA has been successfully applied, so that new users of the approach can meet with people who have successfully applied the PMCA, see the results for themselves, and appreciate the importance of collective action involving diverse market-chain actors.

\section{Validity of the PMCA Change Model}

The cases studied provide insufficient evidence to validate the change model underlying the PMCA. Nevertheless, variations in the fidelity of implementation of the PMCA and in progress along the impact pathway provide an opportunity to assess some aspects of the change model. By comparing results where the key components of the intervention were present with results where some components were absent, we may get some sense of the importance of the components. The point of departure is to gauge progress along the hypothesized impact pathway in the four cases and to identify components of the intervention protocol that appear to have influenced results. This analysis is based on the scores for fidelity of implementation and progress along the impact pathway in the four cases (Tables 13.3 and 13.4, respectively) and on the authors' firsthand knowledge of implementation processes and results in the cases. 
TABLE 13.4 Scoring of progress along the PMCA impact pathway

\begin{tabular}{lcccc}
\hline \multirow{2}{*}{ Outcomes and impacts } & \multicolumn{4}{c}{ Scores for each case } \\
\cline { 2 - 5 } & Case 1 & Case 2 & Case 3 & Case 4 \\
\hline MCAs learn and share knowledge & 3 & 2 & 2 & 2 \\
\hline MCAs generate ideas for new businesses & 3 & 2 & 2 & 2 \\
\hline MCAs develop new businesses & 3 & 2 & 2 & 1 \\
\hline $\begin{array}{l}\text { MCAs generate joint technological, commercial, and institutional } \\
\text { innovation }\end{array}$ & 3 & 2 & 1 & 1 \\
\hline MCAs improve interpersonal relations and trust & 3 & 1 & 1 & 2 \\
\hline MCAs improve use of market information & 2 & 2 & 2 & 2 \\
\hline Services become better oriented to the needs of MCAs & 2 & 2 & 2 & 2 \\
\hline MCAs establish new commercial channels & 2 & 2 & 2 & 1 \\
\hline MCAs use collective action to respond to market demands & 2 & 1 & 1 & 1 \\
\hline MCAs develop multistakeholder platforms & 1 & 1 & 1 & 1 \\
\hline Smallholders improve their technology to fit market demand & 2 & 1 & 1 & 1 \\
\hline Smallholders expand their market network & 2 & 1 & 1 & 0 \\
\hline More favorable policies for market-chain development & 1 & 1 & 1 & 1 \\
\hline Smallholders expand their sales and receive higher prices & 1 & 1 & 1 & 0 \\
\hline
\end{tabular}

Source: Authors.

Notes: 0 = no progress; 1 = limited progress; 2 = moderate progress; 3 = substantial progress; MCA = market-chain actor.

The case that was implemented with greatest fidelity was Case 1 (coffee processing in Peru). This case, in which most activities in the intervention protocol were implemented with reasonable or high fidelity, provides the best test of the validity of the PMCA change model. In this case, the PMCA facilitator was highly motivated and capable, facilitating substantial progress along the impact pathway. Market-chain actors learned and shared knowledge on a number of topics related to market-chain innovation. They developed a new brand of coffee and developed a new business around this idea. Implementation of this new business stimulated and entailed innovations in coffee harvesting, grading, toasting, grinding, packaging, and marketing. As the PMCA was implemented, market-chain actors strengthened interpersonal relations and mutual trust, and afterward many have continued to work together on common goals. Due to the relatively small scale of the intervention in Case 1 and the time required for new practices to diffuse throughout the local economy, at the time of the evaluation the PMCA had not yet had a significant impact on the welfare of the small-scale coffee 
producers. As the volume of sales of the new coffee brands increases in the future, larger welfare impacts can be expected.

In the other three cases, where the fidelity of implementation was lower, less progress was also made along the impact pathway. Useful knowledge was acquired by participants, who also made contacts with other marketchain actors and service providers. Smallholders expanded their knowledge of markets, market actors, and consumer requirements. $\mathrm{R} \& \mathrm{D}$ professionals learned a new approach for promoting market innovation and development, and farmer organizations were strengthened to some extent. However, in these cases, success in marketing new products has been limited. As indicated in the previous section, many factors have influenced the success of the PMCA. However, in these cases, and also in other cases studied in Uganda and Indonesia (Mayanja et al. 2012; Horton et al. 2013), success of the PMCA has been associated with one key component of the action model: engaging processors and other market agents in the PMCA exercise. Engagement of market agents seems to be the most critical single component of the PMCA.

Although high fidelity of implementation was associated with greater progress along the impact pathway, a thorough assessment of the validity of the PMCA change model would require additional evaluations where the approach was implemented with high fidelity under a range of conditions related to the macro environment, the type of market chain, personal attributes of participants, and local rules in use. Such a thorough assessment under what would constitute artificial conditions (not allowing local implementers to adapt the intervention in any way to fit local conditions and meet local needs) would be a complex and costly exercise, for which local partners and international donors have little interest. As Chen (2010) points out, such rigorous assessments of validity are of interest mainly to researchers. Potential users of the PMCA — of any development program for that matterare primarily interested in knowing if it would be viable and effective in meeting political, organizational, and community needs under their particular circumstances. For these reasons, CIP has partnered with donors and R\&D organizations in different parts of the world to test the PMCA under their own conditions and then has conducted case studies to assess the results.

\section{Lessons}

In this section we present four lessons for planning, managing, and evaluating programs that employ the PMCA or similar participatory approaches. 
1. Explicit action and change models for participatory approaches, although challenging to develop, are useful aids for planning, management, and evaluation. Participatory approaches tend to be vaguely defined, as are the ways they are expected to contribute to outcomes. The lack of explicit program theories makes it difficult to monitor implementation and evaluate results. To our knowledge, this is the first case where designers of a participatory intervention have worked with evaluators and prospective implementers to prepare an explicit implementation protocol and impact pathway. These instruments were useful guides for implementation and evaluation, and they provided a basis for reflection and learning. In development projects with limited resources and tight deadlines, it is difficult to justify the time and resources needed to develop action and change models. For this reason, developers of participatory interventions should allocate "research resources" for the elaboration of action and change models that can later be refined and tested by local implementers. The action models should include intervention protocols, as well as indications of how these should be used by implementers working with target populations in specific contexts.

2. When introducing a new participatory approach, fidelity of implementation should be carefully monitored to detect creative adaptations, lapses, and true infidelities. We found three types of deviations from the implementation protocol that are generally lumped together under the heading of "infidelities." Lapses occur when implementers do not understand the intervention well or do not have the skills or resources to implement it correctly; creative adaptations are useful deviations from the implementation protocol which improve the fit of the intervention to local conditions and improve its performance. True infidelities occur when implementers intentionally violate basic principles of the intervention, and are, in effect, implementing another intervention. It is important for managers to know which types of deviation from the intervention protocol are occurring in order to respond appropriately. Early knowledge of lapses can allow managers to provide additional training, coaching, or resources for local teams that needed additional support. Creative adaptations made by one team could be encouraged and shared with other teams. Knowledge of true infidelities could trigger efforts to negotiate a reorientation of the work with the local team or terminate the collaboration expeditiously. Information gained through this type 
of monitoring would have been useful for later interpretation of results of the cases.

\section{For participatory approaches, detailed baseline studies of household live-} lihood and assets may be of limited use for evaluation. "Good evaluation practice" is often assumed to include the gathering of detailed baseline data on the welfare of target beneficiaries and control groups, which will allow measurement of the net impacts of the intervention. However, it needs to be kept in mind that in the real world, resources for evaluation are generally available only during the life of the program. In the Andean Change Alliance, baseline studies generated information that proved useful for planning and fine-tuning local interventions. But due to the long and complex pathways through which the PMCA contributes to outcomes, insufficient time elapsed during the life of the program for measurable impacts to be registered on household welfare and assets. Consequently, we derived relatively little benefit from the substantial investment we made in baseline-data gathering. Those who plan and manage programs employing participatory approaches need to consider the relative costs and benefits of alternative methods for data gathering and choose the most appropriate one for their own circumstances (Bamberger, Rugh, and Mabry 2012).

4. Adequate capacity strengthening needs to be provided to ensure that local implementers can distinguish between core principles and essential components of the intervention and suggested procedures that may be adjusted to fit local circumstances. Participatory R\&D approaches such as the PMCA are knowledge-intensive and local implementers cannot be expected or encouraged to implement them mechanically. Variations in socioeconomic, environmental, and institutional conditions make adaptations in implementation procedures desirable. Additionally, participation is inextricably linked to notions of local autonomy, empowerment, and creativity. For these reasons, local implementers need to understand the basic principles underlying a participatory approach and know which components are essential for its success. This highlights the importance of adequate training, knowledge sharing, and related aspects of local capacity strengthening for the successful introduction of a new participatory approach. 


\section{Conclusion}

In the work reported on here, we applied evaluative thinking to assess the implementation and outcomes of a participatory approach in the field of agricultural R\&D. While common in evaluation practice, the use of action and change models had not to our knowledge been rigorously applied in this field. So, although we originally published this paper in a journal on evaluation and program planning, we believe it will also be of interest to agricultural R\&D professionals. Good quality of implementation of participatory approaches is vital to increase the probability that they can achieve their intended results. But what counts as "good" and how can this be achieved without stifling the creativity and adaptation needed for a participatory approach to work at all? The distinction we draw between creative adaptations, lapses, and true infidelities—grounded in the action model and making the link to outcomes in the change model-helps answer this tricky question. We believe this kind of thinking is of broader relevance both to evaluators and to practitioners of agricultural R\&D.

\section{References}

Alvarez, S., B. Bucheli, R. Delgado, L. Maldonado, R. Paz, A. Pozo, E. Rotondo, et al. 2008. Guia para Estudios de Alcances e Impactos de las Metodologías Participativas Sobre la Innovación Rural. Lima, Peru: Programa Alianza Cambio Andino.

Alvarez, S., B. Douthwaite, G. Thiele, R. Mackay, D. Cordoba, and K. Tehelen. 2010. "Participatory Impact Pathways Analysis: A Practical Method for Project Planning and Evaluation." Development in Practice 20: 946-958.

Antezana, I., T. Bernet, G. Lopez, and R. Oros. 2008. Enfoque Participativo en Cadenas Productivas: Guia para Capacitadores. Lima, Peru: International Potato Center.

Ashley, S. 2009. “Innovation Diffusion: Implications for Evaluation.” New Directions for Evaluation 124: 35-45.

Bamberger, M, J. Rugh, and L. Mabry. 2012. Real World Evaluation: Working under Budget, Time, Data, and Political Constraints. Los Angeles, CA: Sage Publications.

Bernet, T., G. Thiele, and T. Zschocke, eds. 2006. Participatory Market Chain Approach (PMCA): User Guide. Lima, Peru: International Potato Center.

Bierman, K. 2006. "Commentary on the Pitfalls and Pratfalls of Evaluation Research with Intervention and Prevention Programs." New Directions for Evaluation 110: 87-96.

Bisset, S., M. Daniel, and L. Potvin. 2009. "Exploring the Intervention-Context Interface: A Case from a School-Based Nutrition Intervention." American Journal of Evaluation 30: 554-571. 
Century, J., M. Rudnick, and C. Freeman. 2010. “A Framework for Measuring Fidelity of Implementation: A Foundation for Shared Language and Accumulation of Knowledge." American Journal of Evaluation 31: 199-218.

Chambers, R. 2010. Paradigms, Poverty and Adaptive Pluralism. IDS Working Paper 334. Brighton, UK: Institute of Development Studies.

Chen, H. 2005. Practical Program Evaluation. Thousand Oaks, NJ: Sage Publications. . 2010. "The Bottom-Up Approach to Integrative Validity: A New Perspective for Program Evaluation." Evaluation and Program Planning 33: 205-214.

Collinson, M., ed. 2000. A History of Farming Systems Research. Wallingford, UK and New York: $\mathrm{CAB}$ International.

Douthwaite, B., S. Alvarez, S. Cook, R. Davies, P. George, J. Howell, R. Mackay, et al. 2007. "Participatory Impact Pathways Analysis: A Practical Application of Program Theory in Research-for-Development." Canadian Journal of Program Evaluation 22: 127-159.

Devaux, A., D. Horton, C. Velasco, G. Thiele, G. López, T. Bernet, I. Reinoso, et al. 2009. "Collective Action for Market Chain Innovation in the Andes." Food Policy 34: 31-38.

Horton, D., R. Oros, R. Paz Ybarnegaray, G. Lopez, C. Velasco, F. Rodriguez, E. Escobar, et al. 2011. The Participatory Market Chain Approach: Experiences and Results in Four Andean Cases. CIP Social Sciences Working Paper 2011-1. Lima, Peru: International Potato Center.

Horton, D., D. Campilan, B. Prasetya, H. Gani, M. R. Pakih, and Kusmana. 2013 Market Chain Development in Indonesia: Experiences with the "Participatory Market Chain Approach," "Farmer Business Schools," and "Business Development Services." CIP Social Sciences Working Paper, No. 2013-1. Lima, Peru: International Potato Center.

Johnson, N., N. Lilja, and J. Ashby. 2003. "Measuring the Impact of User Participation in Agricultural and Natural Resource Management Research.” Agricultural Systems 78: 287-306.

Lilja, N., and J. Dixon. 2008a. "Operationalising Participatory Research and Gender Analysis: New Research and Assessment Approaches.” Development in Practice 18: 467-478.

_. 2008b. "Responding to the Challenges of Impact Assessment of Participatory Research and Gender Analysis." Experimental Agriculture 44: 3-19.

Martin, A. 2009. "So What Difference Does It Make? Assessing the Outcomes and Impacts of Farmer Participatory Research.” In Farmer First Revisited: Innovation for Agricultural Research and Development, edited by I. Scoones, and J. Thompson. Bourton on Dunsmore, UK: Practical Action Publishing.

Mayanja, S., B. Akello, D. Horton, D. Kisauzi, and D. Magala. 2012. "Value Chain Development in Uganda: Lessons from the Participatory Market Chain Approach.” Banwa 9 (1/2). 
Mowbray, C., M. Holter, G. Teague, and D. Bybee. 2003. "Fidelity Criteria: Development, Measurement, and Validation." American Journal of Evaluation 24: 315-340.

Ostrom, E. 2005. Understanding Institutional Diversity. Princeton, NJ: Princeton University Press.

Patton, M. Q. 2011. Developmental Evaluation: Applying Complexity Concepts to Enhance Innovation and Use. New York: The Guilford Press.

Scoones, I., and J. Thompson, eds. 2009. Farmer First Revisited: Innovation for Agricultural Research and Development. Bourton on Dunsmore, UK: Practical Action Publishing.

Thiele, G., C.A. Quirós, J. Ashby, G. Hareau, E. Rotondo, G. López, R. Paz Ybarnegaray, et al., eds. 2011. Métodos Participativos Para la Inclusión de los Pequeños Productores Rurales en la Innovación Agropecuaria: Experiencias y Alcances en la Región Andina 2007-2010. Lima, Peru: Programa Alianza Cambio Andino.

World Bank. 1996. The World Bank Participation Sourcebook. Washington, DC.

_.2012. Agricultural Innovation Systems: An Investment Sourcebook. Washington, DC.

Yin, R. 2009. Case Study Research. Thousand Oaks, CA: Sage Publications.

Zvoch, K. 2012. "How Does Fidelity of Implementation Matter? Using Multilevel Models to Detect Relationships Between Participant Outcomes and the Delivery and Receipt of Treatment." American Journal of Evaluation 33: 547-565. 